\title{
Evidence that the Severity of Depletion of Inorganic Phosphate Determines the Severity of the Disturbance of Adenine Nucleotide Metabolism in the Liver and Renal
} Cortex of the Fructose-Loaded Rat

\author{
R. Curtis Morris, Jr., Kathleen Nigon, and Elizabeth B. Reed, The \\ Departments of Medicine and Pediatrics, University of California, San Francisco, \\ California 94143
}

\begin{abstract}
A B S T R A C T To test the hypothesis that in both the liver and renal cortex of the fructose-loaded rat, severity of depletion of inorganic phosphate $\left(P_{i}\right)$, and not the magnitude of accumulation of fructose-1-phosphate (F-1-P), determines the severity of the dose-dependent reduction of ATP, we intraperitoneally injected fed rats with fructose, 20 and $40 \mu \mathrm{mol} / \mathrm{g}$, alone, and at the higher load, in combination with $(a)$ sodium phosphate, $20 \mu \mathrm{mol} / \mathrm{g}$, administered shortly beforehand or subsequently or, $(b)$ adenosine, $2 \mu \mathrm{mol} / \mathrm{g}$, administered beforehand. The following observations were made: $(a)$ With fructose loading alone, at the higher load, both $P_{i}$ and total adenine nucleotides (TAN) were reduced by one third in the renal cortex and (as previously observed) by two thirds in the liver; and at either load, the reduction of ATP (and TAN) and the accumulation of F-1-P were less severe in the renal cortex than in the liver. (b) Prior phosphate loading largely prevented the reductions of ATP and TAN in the renal cortex and significantly attenuated them in the liver, yet doubled the renal cortical accumulation of F-1-P. (c) Adenosine loading substantially attenuated the reductions of ATP, TAN, and $P_{i}$ only in the renal cortex. (d) ATP varied directly with $\mathrm{P}_{1}(P<0.001, r=0.98)$ in the domain of control and reduced values of $P_{i}$ taken from both liver and renal cortex. ( $e$ ) As judged from tissue and plasma concentrations of fructose and glucose, and tissue concentrations of fructose-6-phosphate and glucose-6-phosphate, the rate at which the renal cortex and liver converted fructose to glucose was much lower at the higher fructose load. $(f)$ Prior phosphate loading prevented this decrease in rate in the renal cortex and attenuated it in the liver; adenosine loading attenuated
\end{abstract}

Received for publication 20 June 1977 and in revised form 22 August 1977. it only in the renal cortex. We conclude that in both the renal cortex of the fructose-loaded rat: (a) Depletion of $P_{i}$ is critical to the causation of the reductions in both ATP and TAN and, at the higher fructose load, of a decrease in the rate at which ATP is regenerated. (b) The severity of depletion of $P_{i}$ determines the severity of these disturbances. (c) By differentially mitigating the depletion of $P_{i}$, prior phosphate loading largely prevents these disturbances in the renal cortex, and attenuates them in the liver; and adenosine loading attenuates them only in the renal cortex.

The findings provide some basis for the observation that in patients with hereditary fructose intolerance experimentally exposed to fructose, prior loading with sodium phosphate substantially attenuates the renal but not hepatic dysfunction.

\section{INTRODUCTION}

In patients with hereditary fructose intolerance (HFI), ${ }^{1}$ the administration of even small amounts of fructose induces within minutes dose-dependent metabolic and physiologic abnormalities that depend upon cellular accumulation of fructose-1-phosphate (F-1-P) in tissues genetically deficient in aldolase activity toward F-1-P: liver $(1,2)$, renal cortex (3), and small bowel (4). For each mole of fructose converted to F-1-P, 1 mol of ATP is hydrolyzed. In effect, the accumulation of F-1-P depletes cellular inorganic phosphate $\left(P_{i}\right)(1)$. In consequence of the magnitude and rapidity of this depletion, hypophosphatemia occurs almost immedi-

${ }^{1}$ Abbreviations used in this paper: F-1-P, fructose-1-phosphate; F-6-P, fructose-6-phosphate; G-6-P, glucose-6-phosphate; HFI, hereditary fructose intolerance; $P_{i}$, inorganic phosphate; TAN, total adenine nucleotides. 
ately after fructose is initiated (1). In rapid succession thereafter there occur hyperuricemia $(5,6)$ and a complex dysfunction of the renal tubule like that of Fanconi's syndrome $(6,7)$. Although F-1-P can inhibit the activity of enzymes important to normal metabolism in the liver and renal cortex (8-13), a number of observations suggest that depletion of $P_{i}$ in these tissues could be critical to the pathogenesis of both the hyperuricemia and the renal tubular dysfunction $(14,15)$.

In the liver of the fructose-loaded rat, cellular accumulation of F-1-P accounts for the large reduction in hepatic $P_{1}$ that occurs within a minute of administering fructose (16). The reduction in $P_{1}$ just precedes and attends the occurrence of hyperuricemia (and hyperallantoinemia) and a large reduction in the hepatic concentrations of ATP and total adenine nucleotides (TAN) (16-20). In both normal man and the rat, fructose-induced hyperuricemia appears to result from increased degradation of preformed hepatic adenine nucleotides $(16,20-24)$. Normal tissue concentrations of $P_{i}$ inhibit AMP deaminase $(25,26)$. Thus, a fructose-induced depletion in hepatic $P_{i}$ could increase the degradation of AMP to inosine $5^{\prime}$ monophosphate $(16,17)$, a precursor of uric acid (and allantoin) via inosine (16-18), and could restrict the regeneration of hepatic ATP, both by the depletion of $P_{i}$ per se (27), and by the reduction of TAN that depletion entrains (16-19). Similarly, in the renal cortex of the fructose-loaded rat, the accumulation of F-1-P and reduction of ATP (19) might be causally linked through the agency of a depletion of renal cortical $P_{i}$ (15).

Published data, however, provide little or no evidence that phosphate loading ameliorates the disturbances of hepatic metabolism observed either in patients with HFI exposed to fructose or in the fructose-loaded rat $(20,28-30)$. Yet, in patients with HFI, the experimental renal tubular dysfunction induced by fructose is greatly attenuated by prior phosphate loading (15). In contrast to the liver (31), the proximal renal tubule, which forms the bulk of the renal cortex (32), has a high affinity, high capacity, transepithelial transport system for phosphate $(33,34)$. Accordingly, in both the patients with HFI exposed to fructose, and in the fructose-loaded rat, the depletion of $P_{1}$ induced in the renal cortex, and hence the disturbance of adenine nucleotide metabolism in this tissue, might be both less severe than that induced in the liver and more susceptible to attenuation by phosphate loading, and by adenosine loading (vide infra). The presently reported findings in the fructose-loaded rat are those predicted by this hypothesis.

\section{METHODS}

Animals. Male rats of the Sprague-Dawley strain were purchased from Simonsen Laboratories (Gilroy, Calif.), and housed in cages containing wood shavings for bedding, two rats per cage. Room lighting was controlled to produce $12 \mathrm{~h}$ of darkness $(6$ p.m. -6 a.m.) and $12 \mathrm{~h}$ of light. The rats were fed ad libitum laboratory chow (Berkeley Diet, Feedstuffs Processing Co., San Francisco, Calif.). At the time of the experiments they weighed $190-200 \mathrm{~g}$.

Experimental procedures. Rats were anesthetized with pentobarbital sodium (Diabutal, Diamond Labs, Des Moines, Iowa), $55 \mu \mathrm{g} / \mathrm{g}$ body weight, administered intraperitoneally at 9:30 a.m. At approximately 10:00 a.m. solutions for administration were brought to $37^{\circ} \mathrm{C}$ and injected intraperitoneally over $1 \mathrm{~min}$. Fructose $(2.78 \mathrm{M})$ was administered in a dose of 20 or $40 \mu \mathrm{mol} / \mathrm{g}$ body weight, alone and, at the higher dose, in combination with $(a)$ sodium phosphate $\left(2.5 \mathrm{M}, \mathrm{Na}_{2} \mathrm{HPO}_{4} / \mathrm{NaH}_{2} \mathrm{PO}_{4}, \mathrm{pH} 7.4\right)$ in a dose of $20 \mu \mathrm{mol} / \mathrm{g}$ body weight and (or) (b) adenosine (dissolved by heating to $90^{\circ} \mathrm{C}$ and cooled to $37^{\circ} \mathrm{C}$ just before administration) at a dose of $2 \mu \mathrm{mol} / \mathrm{g}$ body weight. Sodium phosphate was administered with fructose in three temporal combinations: coincident with the initiation of fructose, 1.5 to 5 min afterward, and 1.5 to 5 min beforehand. The results of experiments in which the administration of fructose coincided with, or preceded that of, sodium phosphate did not differ from each other and these combinations of sequences have been grouped together as a single experimental group designated fructose/phosphate. The results of experiments in which the administration of sodium phosphate preceded that of fructose differed substantially from those of the fructose/ phosphate group and this sequence of combination is designated phosphate/fructose. The combination is designated fructose-phosphate when the sequence of administration was irrelevant to the results of concern. Adenosine was administered $15 \mathrm{~min}$ before administration of fructose. When adenosine and sodium phosphate were both administered in combination with fructose, the phosphate solution was administered $5 \mathrm{~min}$ before that of fructose. In a number of experiments sodium phosphate or adenosine were administered alone. In several studies, glucose or galactose alone were administered at a dose of $40 \mu \mathrm{mol} / \mathrm{g}$ body weight. Control rats were anesthetized only.

30 min after administration of fructose (or other test substance, when given without fructose) the abdomen was opened, the liver and kidneys rapidly exposed, and the surfaces rinsed free of residual peritoneal fluid with $0.9 \%$ $\mathrm{NaCl}$. Several small samples (30-80 $\mathrm{mg}$ each) of liver were freeze-clamped in situ, with tongs pre-cooled in liquid nitrogen, and each sample was immediately placed in liquid nitrogen. Multiple samples of renal cortex were obtained in a similar manner. To prevent or minimize inclusion of renal medullary tissue, care was taken to clamp tissue to a depth of only $2-3 \mathrm{~mm}$ from the intact kidney surface. The frozen tissue (250-400 $\mathrm{mg}$ ) was rapidly weighed, then ground to a fine powder for which a porcelain mortar and pestle previously chilled in $\mathrm{CO}_{2}$-acetone were employed. To the mortar containing the frozen tissue powder, $10 \mathrm{vol}(\mathrm{wt} / \mathrm{vol})$ of cold $6 \%(\mathrm{wt} / \mathrm{vol})$ perchloric acid was added in a dropwise fashion that allowed the acid to freeze before it contacted the tissue. The frozen tissue powder and frozen acid were then rapidly ground together; the frozen mixture was transferred to a glass homogenizer chilled to $4^{\circ} \mathrm{C}$, thawed, then briefly homogenized at $4^{\circ} \mathrm{C}$, and centrifuged. The supernatant fluid was removed by pipette, neutralized to $\mathrm{pH}$ 6-7 by addition of $5 \mathrm{M} \mathrm{K}_{2} \mathrm{CO}_{3}$ at room temperature, and placed in an ice bath for $30 \mathrm{~min}$. The $\mathrm{KClO}_{4}$ precipitate was removed by centrifugation and the supernatant fluid kept at $4^{\circ} \mathrm{C}$ until used, or frozen and assayed later, the stability of the metabolite to be measured having been determined previously.

As soon as tissue samples had been obtained, blood was withdrawn from the heart into a heparinized syringe; plasma 
was separated by centrifugation at $4^{\circ} \mathrm{C}$; plasma protein was removed by precipitation with $9 \mathrm{vol}(\mathrm{vol} / \mathrm{vol})$ cold $6 \%$ (wt/ vol) perchloric acid. After centrifugation at $4^{\circ} \mathrm{C}$, the proteinfree extract was neutralized to $\mathrm{pH}$ 6-7 by addition of $5 \mathrm{M}$ $\mathrm{K}_{2} \mathrm{CO}_{3}$, the $\mathrm{KClO}_{4}$ precipitate was removed by centrifugation, and the supernatant fluid was used to measure glucose, fructose, and $P_{i}$.

Assays of metabolites. ATP was measured by the luciferase method (35), using firefly extract (Worthington Biochemical Corp., Freehold, N. J.) and a Chem-Glo photometer (American Instrument Co., Travenol Laboratories Inc., Silver Springs, Md.). Pyruvate, ADP and AMP were determined by the combined assay of Adam (36). $P_{1}$ was measured by two methods $(37,38)$, with good agreement. The fluorometric methods of Burch et al. (19) and of Lowry et al. (39) were used to determine fructose-1-phosphate and $\alpha$-glycerolphosphate, respectively. Glucose and fructose were measured as described by Klotzsch and Bergmeyer (40); glucose-6-phosphate and fructose-6-phosphate by the method of Hohorst (41), or fluorometrically (39). The majority of chemicals and enzymes used for the assays were purchased from Sigma
Chemical Corp., St. Louis, Mo., and Boehringer Mannheim Corp., New York. Metabolite concentrations are expressed as micromoles per gram of wet tissue.

\section{RESULTS}

\section{Control studies}

The control and experimental values with fructose alone, $40 \mu \mathrm{mol} / \mathrm{g}$ body weight, for hepatic and renal cortical concentrations of ATP and F-1-P (Tables I and II) are virtually identical to those reported by Burch et al. (17); the values for hepatic concentrations of TAN and $P_{i}$ are also in good agreement. Although the concentrations of both ATP and TAN are significantly lower in the renal cortex than in the liver, the concentrations of $P_{i}$ and the values of adenylate energy charge (26) are virtually the same

TABLE I

Effect of Fructose, Phosphate, and Adenosine, and Combinations Thereof, on the Concentrations of Certain Metabolites in the Rat Renal Cortex and Plasma, and on the Derived Values of Adenylate "Energy

Charge" and the Adenylate Kinase Mass Action Ratio

\begin{tabular}{|c|c|c|c|c|c|c|c|c|c|}
\hline $\begin{array}{l}\text { Test solution } \ldots \ldots \ldots \ldots \\
\text { Dose, } \mu \mathrm{mol} / \mathrm{g}\end{array}$ & Control & Fructose & Fructose & $\begin{array}{l}\text { Phosphate/ } \\
\text { fructose }\end{array}$ & $\begin{array}{l}\text { Fructose/ } \\
\text { phosphate }\end{array}$ & Phosphate & Adenosine & $\begin{array}{l}\text { Adenosine/ } \\
\text { fructose }\end{array}$ & $\begin{array}{c}\text { Adenosine/ } \\
\text { phosphate/ } \\
\text { fructose }\end{array}$ \\
\hline $\begin{array}{c}\text { body } \boldsymbol{w t} \ldots \ldots \ldots \ldots \ldots \ldots \\
(\boldsymbol{n}) \ldots \ldots \ldots \ldots \ldots \ldots\end{array}$ & (11) & $\begin{array}{l}20 \\
(6)\end{array}$ & $\begin{array}{c}40 \\
(11)\end{array}$ & $\begin{array}{c}20 / 40 \\
(10)\end{array}$ & $\begin{array}{c}40 / 20 \\
(10)\end{array}$ & $\begin{array}{l}20 \\
(2)\end{array}$ & $\begin{array}{c}2 \\
(3)\end{array}$ & $\begin{array}{c}2 / 40 \\
(5)\end{array}$ & $\begin{array}{l}2 / 20 / 40 \\
(4)\end{array}$ \\
\hline
\end{tabular}

\begin{tabular}{|c|c|c|c|c|c|c|c|c|c|}
\hline \multicolumn{10}{|c|}{$\mu \mathrm{mol} / \mathrm{g}$ wet $w t$} \\
\hline \multicolumn{10}{|c|}{$\begin{array}{l}\text { Renal cortex } \\
\text { Metabolites }\end{array}$} \\
\hline ATP & $2.46 \pm 0.25$ & $1.99 \pm 0.28 \rrbracket$ & $1.26 \pm 0.12^{*}$ & $2.03 \pm 0.33^{*}$ & $1.61 \pm 0.36 \S$ & $2.35 \pm 0.13$ & $3.35 \pm 0.30^{*}$ & $1.67 \pm 0.06^{*}$ & $2.07 \pm 0.47 \S$ \\
\hline ADP & $0.57 \pm 0.10$ & $0.67 \pm 0.13$ & $0.75 \pm 0.13 \ddagger$ & $0.63 \pm 0.15$ & $0.66 \pm 0.15$ & $0.66 \pm 0.029$ & $0.90 \pm 0.10^{*}$ & $0.81 \pm 0.27$ & $0.71 \pm 0.08$ \\
\hline AMP & $0.15 \pm 0.09$ & $0.14 \pm 0.03$ & $0.15 \pm 0.04$ & $0.23 \pm 0.08 \S$ & $0.22 \pm 0.09^{\prime \prime}$ & $0.32 \pm 0.02 \rrbracket$ & $0.16 \pm 0.05$ & $0.23 \pm 0.081$ & $0.36 \pm 0.09^{*}$ \\
\hline$\Sigma$ & $3.18 \pm 0.28$ & $2.79 \pm 0.381$ & $2.16 \pm 0.16^{*}$ & $2.89 \pm 0.39^{*}$ & $2.47 \pm 0.26 \rrbracket$ & $3.33 \pm 0.21$ & $4.42 \pm 0.24^{*}$ & $2.72 \pm 0.24^{*}$ & $3.15 \pm 0.36^{*}$ \\
\hline $\mathbf{P}_{\mathbf{1}}$ & $2.79 \pm 0.56$ & $2.03 \pm 0.39$ & $1.67 \pm 0.41^{*}$ & $23.60 \pm 4.18^{*}$ & $18.10 \pm 1.66^{*}$ & $42.7 \pm 2.0^{*}$ & $2.83 \pm 0.12$ & $2.14 \pm 0.19 \$$ & $14.08 \pm 6.5 t$ \\
\hline Fru & - & $22.0 \pm 7.0^{*}$ & $54.3 \pm 13.7^{*}$ & $18.6 \pm 7.2^{*}$ & $28.2 \pm 7.2^{*}$ & - & - & $23.3 \pm 4.1^{*}$ & $13.3 \pm 6.3^{*}$ \\
\hline F-1-P & - & $5.4 \pm 1.3^{*}$ & $6.5 \pm 1.0^{*}$ & $11.9 \pm 5.11$ & $13.1 \pm 3.1^{*}$ & - & - & $6.5 \pm 0.5$ & $8.1 \pm 4.8$ \\
\hline GP & $0.1 \pm 0.1$ & $5.3 \pm 1.5^{*}$ & $5.7 \pm 0.8^{*}$ & $8.2 \pm 1.7^{*}$ & $9.3 \pm 1.5^{*}$ & $0.4 \pm 0.1^{\prime \prime}$ & $0.6 \pm 0.3^{\prime \prime}$ & $6.9 \pm 0.6 !$ & $8.5 \pm 1.6 t$ \\
\hline F-6-P & $0.02 \pm 0.00$ & $0.06 \pm 0.03$ & $0.05 \pm 0.03^{\prime \prime}$ & $0.13 \pm 0.05^{*}$ & $0.10 \pm 0.06$ & $0.03 \pm 0.04$ & $0.04 \pm 0.01^{*}$ & $0.06 \pm 0.02$ & $0.09 \pm 0.04^{\prime \prime}$ \\
\hline G-6-P & $0.11 \pm 0.03$ & $0.27 \pm 0.06^{*}$ & $0.18 \pm 0.04^{*}$ & $0.37 \pm 0.08^{*}$ & $0.28 \pm 0.09 !$ & $0.07 \pm 0.03$ & $0.18 \pm 0.01^{*}$ & $0.26 \pm 0.03^{*}$ & $0.28 \pm 0.08$ \\
\hline Glu & $5.9 \pm 0.7$ & $10.5 \pm 1.8^{*}$ & $8.9 \pm 1.8 \ddagger$ & $13.2 \pm 3.2 \ddagger$ & $12.1 \pm 2.8 \S$ & $9.7 \pm 1.3 \S$ & $10.4 \pm 0.8^{*}$ & $11.4 \pm 1.6^{\prime \prime}$ & $16.2 \pm 2.7^{*}$ \\
\hline Pyr & $0.20 \pm 0.21$ & $0.22 \pm 0.08$ & $0.27 \pm 0.10$ & $0.36 \pm 0.18$ & $0.44 \pm 0.11 \ddagger$ & $0.29 \pm 0.04$ & $0.16 \pm 0.12$ & $0.24 \pm 0.16$ & $0.24 \pm 0.16$ \\
\hline \multicolumn{10}{|c|}{ Derived values } \\
\hline EC & $0.86 \pm 0.03$ & $0.83 \pm 0.01 *$ & $0.75 \pm 0.04^{*}$ & $0.81 \pm 0.03^{*}$ & $0.78 \pm 0.07$ & $0.82 \pm 0.01^{*}$ & $0.86 \pm 0.01$ & $0.77 \pm 0.02$ & $0.77 \pm 0.06$ \\
\hline \multirow[t]{2}{*}{$\mathbf{A K}$} & $1.25 \pm 0.90$ & $0.67 \pm 0.141$ & $0.33 \pm 0.12 \ddagger$ & $1.32 \pm 0.65^{*}$ & $0.94 \pm 0.71^{\prime \prime}$ & $1.74 \pm 0.33$ & $0.71 \pm 0.35$ & $0.78 \pm 0.63$ & $1.44 \pm 0.26^{*}$ \\
\hline & \multicolumn{9}{|c|}{$\mu \mathrm{mol} / \mathrm{ml}$} \\
\hline \multicolumn{10}{|l|}{ Plasma } \\
\hline $\mathbf{P}_{\mathbf{1}}$ & $3.23 \pm 0.25$ & $2.87 \pm 0.48$ & $2.54 \pm 0.29^{*}$ & $28.2 \pm 3.2^{*}$ & $26.90 \pm 3.9^{*}$ & $35.4 \pm 2.3^{*}$ & $2.26 \pm 0.39 \ddagger$ & $2.32 \pm 0.13$ & $24.8 \pm 5.0^{*}$ \\
\hline Fru & - & $9.6 \pm 4.2^{*}$ & $43.2 \pm 8.3^{*}$ & $20.2 \pm 10.8^{*}$ & $25.9 \pm 8.8^{*}$ & - & - & $43.7 \pm 6.4$ & $22.1 \pm 4.3^{*}$ \\
\hline Glu & $9.4 \pm 0.9$ & $14.9 \pm 2.8^{*}$ & $11.6 \pm 3.0$ ㅇ & $15.4 \pm 5.3$ & $14.0 \pm 4.2$ & $18.4 \pm 5.7$ & $15.9 \pm 3.1 \S$ & $13.0 \pm 2.1$ & $19.4 \pm 3.8 \S$ \\
\hline
\end{tabular}

Abbreviations: $\Sigma=$ total adenine nucleotides; Fru = fructose; GP = $\alpha$-glycerolphosphate; Glu = glucose; Pyr = pyruvate; EC = energy charge, ATP + 0.5 ADP/AMP + ADP + ATP; AK = adenylate kinase mass action ratio. All values are means \pm 1 SD. Significance of difference between means was determined by Student's $t$ test. For fructose, adenosine, or phosphate, alone, the difference between the experimental group and the control group was tested. For all other experiments, in which fructose was given in combination with adenosine or with phosphate, the difference between the experimental group and fructose, alone, $40 \mu \mathrm{mol} / \mathrm{g}$, was tested. Code for statistical probabilities used in this Table and in Table II is:

$*=<0.001$.

$t=<0.005$.

$\S=<0.01$.

" $=<0.025$

$\mathbf{I}=<0.05$. 
TABLE II

Effect of Fructose, Phosphate, and Adenosine, and Combinations Thereof, on the Concentrations of Certain Metabolites in the Rat Liver, and on the Derived Values of Adenylate "Energy Charge" and the Adenylate Kinase Mass Action Ratio

\begin{tabular}{|c|c|c|c|c|c|c|c|c|c|}
\hline $\begin{array}{c}\text { Test solution } \\
\text { Dose, } \mu \text { mol/g } \\
\text { body } w t \ldots \\
(n) \ldots \ldots \ldots\end{array}$ & Control & Fructose & $\begin{array}{l}40 \\
(11)\end{array}$ & $\begin{array}{l}\text { Phosphate/ } \\
\text { fructose }\end{array}$ & $\begin{array}{c}\begin{array}{c}\text { Fructose/ } \\
\text { phosphate }\end{array} \\
40 / 20 \\
(10)\end{array}$ & Phosphate & Adenosine & $\begin{array}{c}\begin{array}{c}\text { Adenosine/ } \\
\text { fructose }\end{array} \\
2 / 40 \\
(5)\end{array}$ & $\begin{array}{l}\text { Adenosine/ } \\
\text { phosphate/ } \\
\text { fructose }\end{array}$ \\
\hline & \multicolumn{9}{|c|}{$\mu \mathrm{mol} / \mathrm{g}$ wet $\mathrm{wt}$} \\
\hline Metabolites & & & & & & & & & \\
\hline ATP & $3.45 \pm 0.21$ & $1.43 \pm 0.20^{*}$ & $0.75 \pm 0.11^{*}$ & $1.20 \pm 0.36^{*}$ & $1.10 \pm 0.25^{*}$ & $2.51 \pm 0.20 t$ & $4.68 \pm 0.70 \S$ & $0.95 \pm 0.20 \pi$ & $1.26 \pm 0.26 t$ \\
\hline ADP & $0.78 \pm 0.09$ & $0.50 \pm 0.06^{*}$ & $0.57 \pm 0.09^{*}$ & $0.69 \pm 0.17$ & $0.60 \pm 0.10$ & $1.48 \pm 0.18 t$ & $1.14 \pm 0.32$ & $\begin{array}{l}0.62 \pm 0.12 \\
0.28+0.09\end{array}$ & $\begin{array}{l}0.86 \pm 0.13 \ddagger \\
0.46+0.098\end{array}$ \\
\hline AMP & $0.18 \pm 0.07$ & $0.16 \pm 0.07$ & $0.28 \pm 0.06 \S$ & $0.32 \pm 0.09$ & $0.29 \pm 0.06$ & $0.63 \pm 0.14 \S$ & $0.32 \pm 0.06 \S$ & $0.28 \pm 0.09$ & $0.46 \pm 0.09 \S$ \\
\hline$\Sigma$ & $4.42 \pm 0.25$ & $2.08 \pm 0.14^{*}$ & $1.57 \pm 0.16^{*}$ & $2.21 \pm 0.46^{*}$ & $1.99 \pm 0.15^{*}$ & $4.62 \pm 0.52$ & $6.15 \pm 0.97 \downarrow$ & $1.85 \pm 0.19$ & $2.58 \pm 0.36^{*}$ \\
\hline$P_{1}$ & $2.98 \pm 0.25$ & $1.98 \pm 0.70^{n}$ & $0.92 \pm 0.15^{*}$ & $6.75 \pm 1.22^{*}$ & $6.38 \pm 1.41^{*}$ & $11.85 \pm 2.76 t$ & $2.68 \pm 0.72$ & $1.26 \pm 0.37$ & $6.80 \pm 2.7^{*}$ \\
\hline Fru & - & $4.6 \pm 2.4^{*}$ & $30.7 \pm 7.6^{*}$ & $12.6 \pm 10.1^{*}$ & $16.3 \pm 7.6^{*}$ & - & - & $30.9 \pm 6.4$ & $11.4 \pm 4.2^{*}$ \\
\hline F-1-P & - & $12.8 \pm 3.2^{*}$ & $15.9 \pm 1.5^{*}$ & $15.3 \pm 4.9$ & $14.9 \pm 2.3$ & - & - & $16.9 \pm 1.9$ & $14.8 \pm 4.7$ \\
\hline GP & $0.5 \pm 0.3$ & $1.2 \pm 0.4^{\prime \prime}$ & $1.8 \pm 0.6$ & $3.1 \pm 1.2 \S$ & $3.9 \pm 1.7 \ddagger$ & $1.7 \pm 0.6^{6}$ & $0.5 \pm 0.2$ & $1.6 \pm 0.8$ & $4.0 \pm 0.9^{*}$ \\
\hline F-6-P & $0.06 \pm 0.03$ & $0.17 \pm 0.06 \S$ & $0.08 \pm 0.05$ & $0.17 \pm 0.15$ & $0.13 \pm 0.04 \S$ & $0.37 \pm 0.16 \pi$ & $0.15 \pm 0.04 \S$ & $0.08 \pm 0.03$ & $0.12 \pm 0.06$ \\
\hline G-6-P & $0.23 \pm 0.06$ & $0.43 \pm 0.12 \S$ & $0.16 \pm 0.05 \S$ & $0.52 \pm 0.41 \S$ & $0.38 \pm 0.17^{*}$ & $0.95 \pm 0.06^{*}$ & $0.59 \pm 0.15 \S$ & $0.25 \pm 0.10$ & $0.39 \pm 0.17$ \\
\hline Glu & $7.2 \pm 1.1$ & $14.0 \pm 1.6^{*}$ & $11.0 \pm 2.7^{*}$ & $15.3 \pm 5.19$ & $14.2 \pm 3.5 \pi$ & $20.9 \pm 0.00^{*}$ & $13.4 \pm 2.9 \rrbracket$ & $12.4 \pm 2.4$ & $17.5 \pm 2.8^{*}$ \\
\hline Pyr & $0.19 \pm 0.18$ & $0.50 \pm 0.15^{\prime \prime}$ & $0.44 \pm 0.12^{\prime \prime}$ & $0.55 \pm 0.16 \rrbracket$ & $0.72 \pm 0.15^{*}$ & $0.28 \pm 0.04$ & $0.15 \pm 0.02$ & $0.28 \pm 0.13$ & $0.41 \pm 0.07$ \\
\hline \multicolumn{10}{|l|}{ Derived values } \\
\hline EC & $0.88 \pm 0.22$ & $0.80 \pm 0.05 \S$ & $0.66 \pm 0.07^{*}$ & $0.69 \pm 0.07$ & $0.70 \pm 0.06$ & $0.70 \pm 0.01^{*}$ & $0.85 \pm 0.01^{*}$ & $0.68 \pm 0.06$ & $0.65 \pm 0.04$ \\
\hline AK & $1.05 \pm 0.46$ & $0.93 \pm 0.27$ & $0.67 \pm 0.19$ & $0.83 \pm 0.21$ & $0.92 \pm 0.43$ & $0.72 \pm 0.04$ & $1.27 \pm 0.60$ & $0.73 \pm 0.26$ & $0.79 \pm 0.10$ \\
\hline
\end{tabular}

Abbreviations, statistical groupings, and code for statistical probabilities are the same as those used in Table I.

(Tables I and II). (Burch et al. reported no values for renal cortical concentrations of TAN and $\mathrm{P}_{\mathrm{i}}$.) The control values of hepatic ATP and ADP in the present study are also in good agreement with those reported by Mäenpää, Raivio, and Kekomäki $(18,42)$ and with the "physiologic" values of Faupel et al. (43). The renal cortical concentrations of ATP, ADP, AMP, and $P_{i}$ measured in the present study are somewhat different from those reported by Hems and Brosnan (44) whose technique of tissue sampling may have permitted a greater breakdown of ATP (43).

\section{Effect of fructose on adenine nucleotides, $P_{i}$, and F-1-P}

Fructose alone. In both the liver and renal cortex, administration of fructose alone at doses of 20 and 40 $\mu \mathrm{mol} / \mathrm{g}$ body weight induced dose-dependent reductions of TAN, ATP, and, in the liver, of $P_{i}$ as well. At either fructose load, the reductions of ATP and $P_{i}$ (and the accumulation of F-1-P) were significantly greater in the liver than in the renal cortex. Taken together from both control and experimental conditions of fructose loading alone at both doses (and in combination with adenosine loading [vide infra]), the renal cortical and hepatic concentrations of ATP varied directly with these tissues' concentrations of $P_{i}$ (Tables
I and II). When the values from both tissues were treated as a single set (Fig. 1), the correlation was highly significant $(P<0.001)$, irrespective of whether the set of values was analyzed as an exponential function $(r=0.979)$, or as a linear regression $(r=0.941)$ (not shown).

In the liver, ADP was also substantially reduced at both loads of fructose. In the renal cortex ADP was increased significantly at the higher load of fructose. In the liver, AMP was increased at the higher load of fructose. In the renal cortex, fructose induced a substantial accumulation of $\alpha$-glycerolphosphate which approximated that of F-1-P and greatly exceeded the minimally increased concentration of $\alpha$-glycerolphosphate induced in the liver.

Loading with glucose or galactose alone did not induce changes in renal cortical or hepatic ATP, ADP, or AMP (data not shown).

Fructose with sodium phosphate. With fructosephosphate, the hepatic and renal cortical concentrations of ATP and TAN were significantly greater than those obtaining with the administration of fructose alone, and the renal cortical concentration of F-1-P was doubled (Tables I and II). When the initiation of phosphate preceded that of fructose, by even $90 \mathrm{~s}$, a statistically significant reduction in TAN did not occur in the renal cortex and the reduction of ATP 


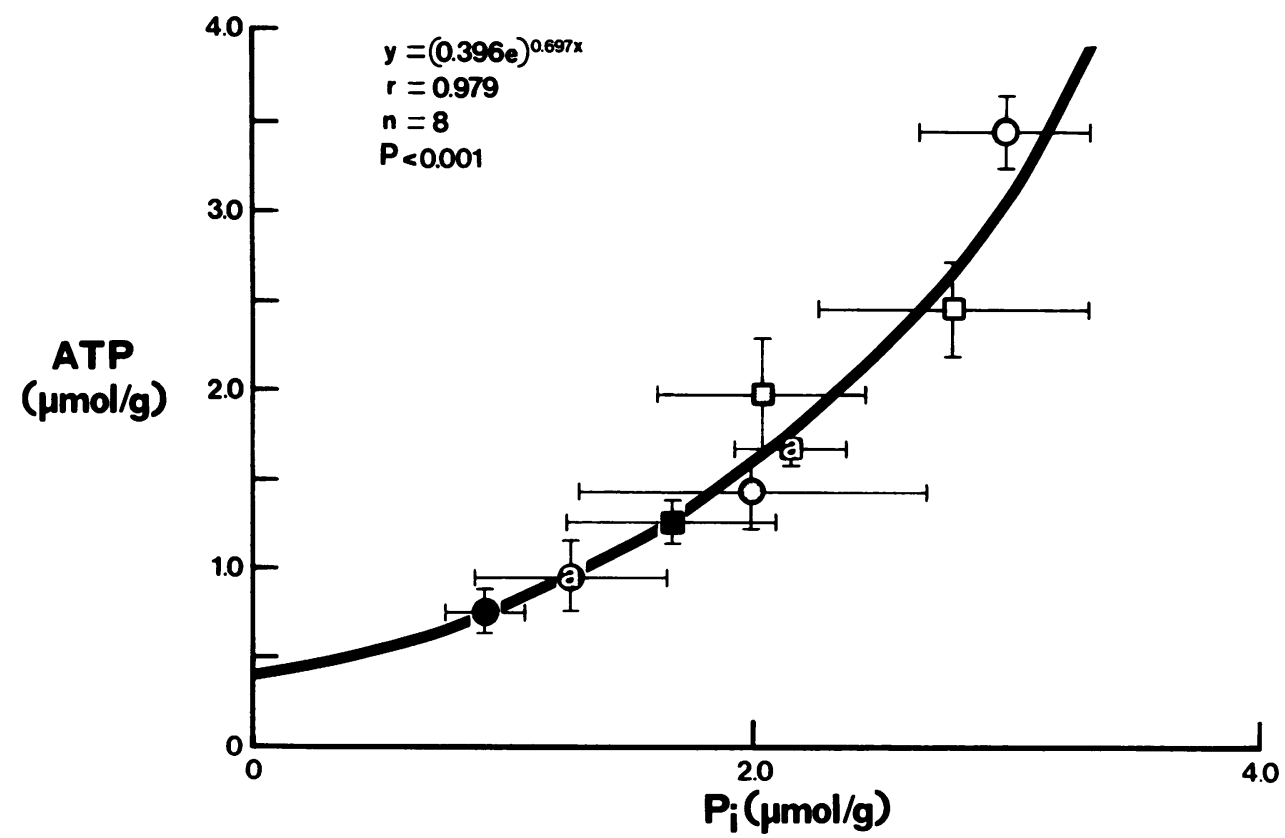

FIGURE 1 The relationship between the concentrations of $P_{1}$ and ATP in the liver (O) and renal cortex $(\square)$ of the intact rat. The result of loading with fructose, alone, at 20 and $40 \mu \mathrm{mol} / \mathrm{g}$, is denoted by shaded and blackened symbols, respectively; that of the higher dose of fructose combined with adenosine, $2 \mu \mathrm{mol} / \mathrm{g}$, is denoted by blackened symbols affixed with the letter "a." Control conditions are denoted by open symbols: The symbols and their brackets represent means \pm 1 SD. The relationship between $P_{1}$ and ATP is direct and significant $(P<0.001)$, whether analysed as the depicted exponential function $(r=0.979)$ or as a linear regression $(r=0.941)$ (not shown).

was modest, the concentrations of both TAN and ATP in the renal cortex being $0.4 \mu \mathrm{mol} / \mathrm{g}$ greater than those obtained with the reverse sequence $(P<0.01)$.

The attenuating effect of phosphate loading on the fructose-induced disturbances in adenine nucleotide metabolism cannot be ascribed to either an increased urinary excretion of fructose or to diminished tissue extraction of fructose: With combined fructose-phosphate loading, irrespective of their sequence of initiation, both the urinary excretion and plasma concentration of fructose were less than with fructose (Table I, Fig. 2). The attenuating effect of phosphate loading cannot be attributed to the increased concentrations of circulating parathyroid hormone that are undoubtedly induced by a reduction in the plasma concentration of ionized calcium consequent to phosphate loading: Administration of parathyroid hormone in supraphysiologic amounts did not attenuate (nor amplify) the fructose-induced abnormalities of adenine nucleotide metabolism in the renal cortex, and the fructose-induced phenomena were unaffected by parathyroidectomy (data not shown).

With phosphate/fructose, relative to fructose loading alone, ADP was decreased and increased in the renal cortex and liver, respectively, and by $0.12 \mu \mathrm{mol} / \mathrm{g}$. Although neither of these changes is statistically signifi- cant, each was correcting in that neither value of ADP with phosphate/fructose was statistically different from that of control, whereas with fructose loading alone

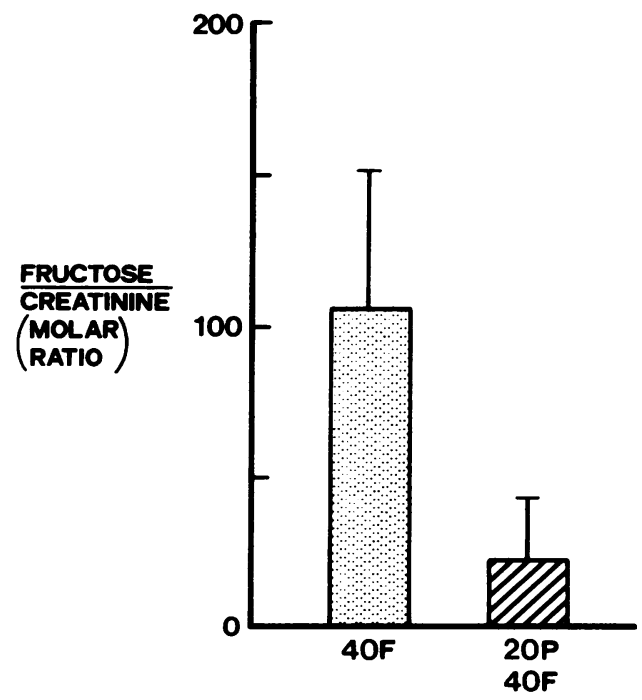

Figure 2 The effect of fructose (F), alone, and in combination with sodium phosphate $(\mathrm{P})$, on the urinary excretion of fructose. The dose of each substance administered is indicated by the number next to its notation. 
ADP was significantly increased and decreased in the renal cortex and liver, respectively. Since the squared concentration of ADP constitutes the denominator of the adenylate kinase mass action ratio, the observed changes in ADP in the renal cortex contribute importantly to the severe reduction of this ratio with fructose alone, and to its restoration to normal with prior phosphate loading.

Fructose with adenosine. Adenosine was employed in the present study as a systemic quasi-ionophore for $P_{i}$. As might have been predicted (4548), adenosine administered alone induced hypophosphatemia and a $40 \%$ increase in both the hepatic and renal cortical concentrations of adenine nucleotides, the increase being predominantly as ATP (and unassociated with a reduction of $P_{i}$ in these tissues). It was reckoned that the nucleotides comprising this increment would release otherwise unavailable $P_{i}$ within the cells of the liver and renal cortex when these tissues either hydrolysed ATP or degraded AMP and its deamination product, inosine 5'-monophosphate, to inosine, reactions presumed to proceed at increased rates with fructose loading (16-23).

With adenosine/fructose loading, the renal cortical, but not hepatic, concentration of $P_{i}$ was significantly higher than that with fructose loading alone, although the severity of hypophosphatemia was not different from that induced by either substance alone. With the combination, the increments in tissue concentrations of ATP and TAN over those obtained with fructose loading alone were significantly greater in the renal cortex than in the liver. Accordingly, with adenosine/ fructose, the concentrations of ATP and TAN in the renal cortex were substantially higher than those in the liver. With the combination adenosine/phosphate/fructose, hepatic and renal cortical ATP and ADP were not higher than those obtained with phosphate/fructose; the concentrations of AMP were slightly higher.

\section{Conversion rate of fructose to glucose}

Changes in the rate at which the liver and renal cortex convert fructose to glucose, and the rate at which ATP is thereby consumed, can be inferred from changes in these tissues' concentrations of fructose and glucose and the obligate metabolic intermediates, fructose-6-phosphate (F-6-P), and glucose-6-phosphate (G-6-P). Administered alone, fructose at the higher dose (40 $\mu \mathrm{mol} / \mathrm{g}$ ) induced increases in hepatic and renal cortical concentrations of glucose and G-6-P that were significantly less than those induced by the lower dose of fructose $(20 \mu \mathrm{mol} / \mathrm{g})$. With the higher dose of fructose, the hepatic and plasma concentrations of fructose reached values more than four times those obtaining at the lower dose of fructose; the renal cortical con- centration of fructose more than doubled. But when the higher dose of fructose was administered in combination with phosphate, the renal cortical and hepatic concentrations of glucose, G-6-P, F-6-P (and F-1-P) were at least as high as those obtaining with the lower dose of fructose; the renal cortical, hepatic, and plasma concentrations of fructose were strikingly less than those obtaining with the higher dose of fructose administered alone. With the combination phosphate/ fructose, the renal cortical, but not hepatic, concentration of fructose was as low as that obtaining with the lower dose of fructose, and significantly less than that obtaining with fructose/phosphate. With the combination phosphate/fructose but not fructose/phosphate, the renal cortical (but not hepatic) concentrations of G-6-P, F-6-P and glucose were significantly higher than those obtaining with the lower dose of fructose administered alone. These findings provide evidence that, when fructose was administered alone, the rate at which both the liver and renal cortex converted it to glucose was substantially lower at the higher dose of fructose, and that phosphate loading prevented the decrease in rate in the renal cortex and attenuated it in the liver.

Interpretation of the observed changes in the liver is complicated by the finding that administration of phosphate alone was attended by a large increase in the plasma concentration of glucose and in the hepatic concentration of glucose, F-6-P and G-6-P and a significant reduction in hepatic ATP (Table II). These findings suggest that phosphate induced an appreciable increase in the rate of glycogenolysis. In the renal cortex, in which the glycogen concentration is minimal (less than $2 \mu \mathrm{mol} / \mathrm{g}$ ) (19), phosphate loading alone did not induce an increase in the concentration of F-6-P or G-6-P or a reduction in the concentration of ATP. The renal cortical concentration of glucose was increased with phosphate loading alone, but to a value only one-half that of plasma glucose and significantly less than those values obtaining with the fructose-phosphate combination.

With adenosine/fructose the renal cortical but not hepatic concentration of fructose was strikingly lower than that with fructose loading alone; the renal cortical but not hepatic concentrations of glucose and G-6-P were significantly higher. With adenosine/phosphate/ fructose, and not with phosphate/fructose, the renal cortical concentration of fructose was significantly lower than that obtaining with the lower dose of fructose alone. With the triple combination, the renal cortical concentration of glucose reached its highest value and was substantially higher $(>50 \%)$ than that obtaining with the lower dose of fructose, whereas with phosphate/fructose, the renal cortical concentration of glucose was just significantly greater than that obtaining with the lower dose of fructose. 


\section{Phosphorus balance}

Fructose administered alone induced a significant reduction in the plasma concentration of $P_{i}$ (Table $I$ ) and a striking net gain in phosphorus in both the liver and renal cortex (Table III, Fig. 3). In both tissues, the decrease in the concentrations of $P_{i}$ and ATP was more than offset by the increase in the combined concentrations of F-1-P and $\alpha$-glycerolphosphate. With the $40 \mu \mathrm{mol} / \mathrm{g}$ dose of fructose, the accumulation of F-1-P alone in the liver was equivalent to the sum of organic plus inorganic phosphorus measured in the control liver (in which F-1-P was not detectable) (Fig. 3); in the renal cortex, the combined concentration of F-1-P and $\alpha$-glycerolphosphate exceeded the total phosphorus measured in the control. With the $40-\mu \mathrm{mol} / \mathrm{g}$ dose of fructose, the calculated net gain in measured acidsoluble phosphrous of liver was $6.7 \mu \mathrm{mol} / \mathrm{g}$ wet wt; in renal cortex, $7.8 \mu \mathrm{mol} / \mathrm{g}$ wet wt (Table III, Fig. 3). The net gain in liver reported by Burch et al. (17) under similar, but not identical, conditions was $8.2 \mu \mathrm{mol}$ phosphorus/g wet wt.

With combined fructose-phosphate loading, the hepatic concentration of F-1-P was not statistically different from that obtaining with fructose alone; the concentration of $\alpha$-glycerolphosphate increased but remained relatively small. By contrast, the renal cortical concentrations of F-1-P and $\alpha$-glycerolphosphate were substantially greater with combined fructose-phosphate loading than with fructose alone, their combined concentration of $20 \mu \mathrm{mol} / \mathrm{g}$ being almost twofold greater. Principally as a consequence of this doubling, the net

TABLE III

Balances of Phosphorus in the Renal Cortex and the Liver: The Effect of Fructose (F), Alone, and in Combination with Sodium Phosphate (P) and Adenosine (A)

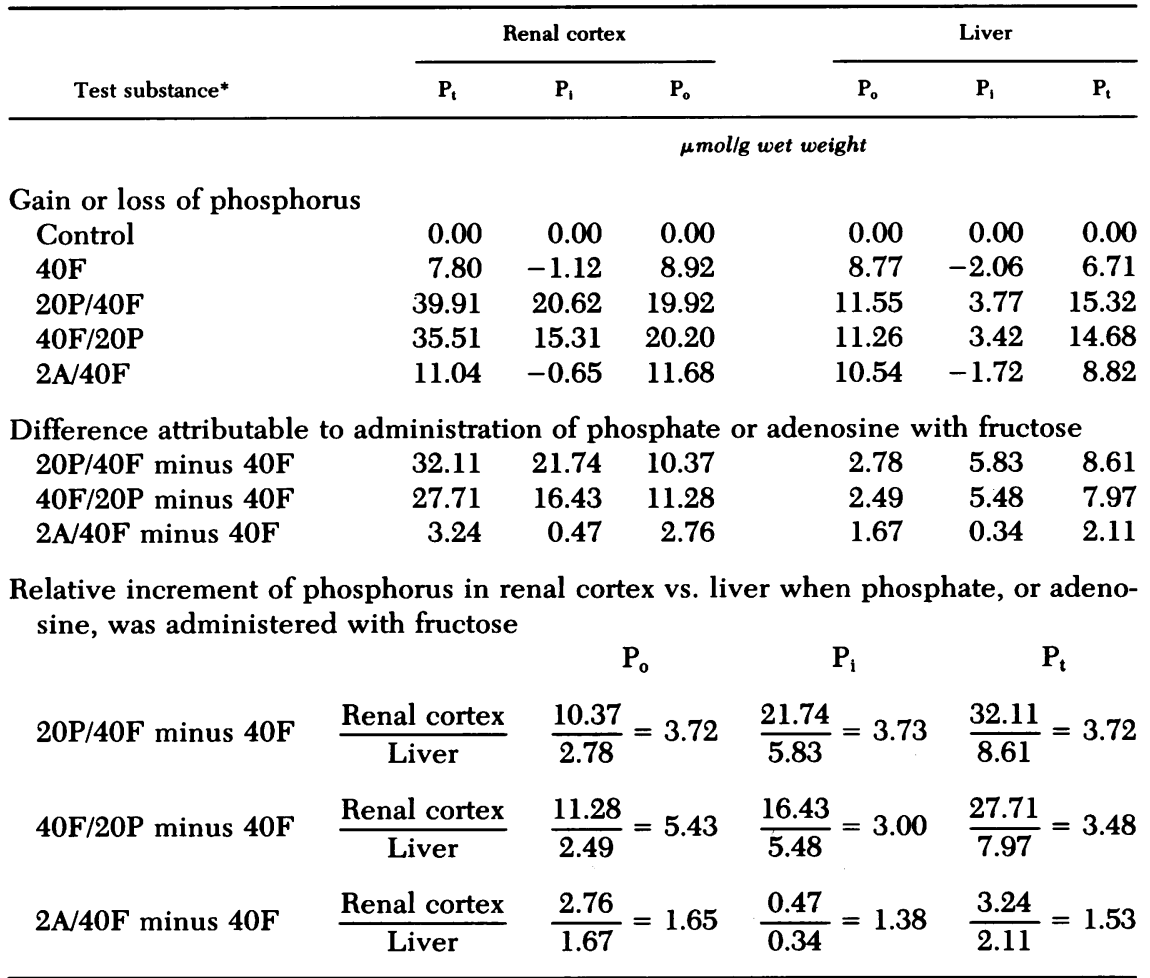

$\mathrm{P}_{0}$, organic phosphorus in $\Sigma \mathrm{ATP}+\mathrm{ADP}+\mathrm{AMP}+\alpha$-glycerolphosphate + fructose-1phosphate + fructose-6-phosphate + glucose-6-phosphate phosphorus; $P_{i}$, inorganic phosphorus; $P_{t}, P_{0}+P_{1}$. Control values for liver were $P_{o}=12.84, P_{i}=2.98, P_{t}=15.82$; for renal cortex, $P_{0}=8.90, P_{1}=2.79, P_{t}=11.69, \mu \mathrm{mol} / \mathrm{g}$ wet wt. All calculations are derived from data of Tables I and II.

* The amount of test substance administered in micromoles per gram is indicated by the number next to its notation. The substance notated as a numerator was administered in combination with, and initiated before that of, the substance notated as the denominator. 


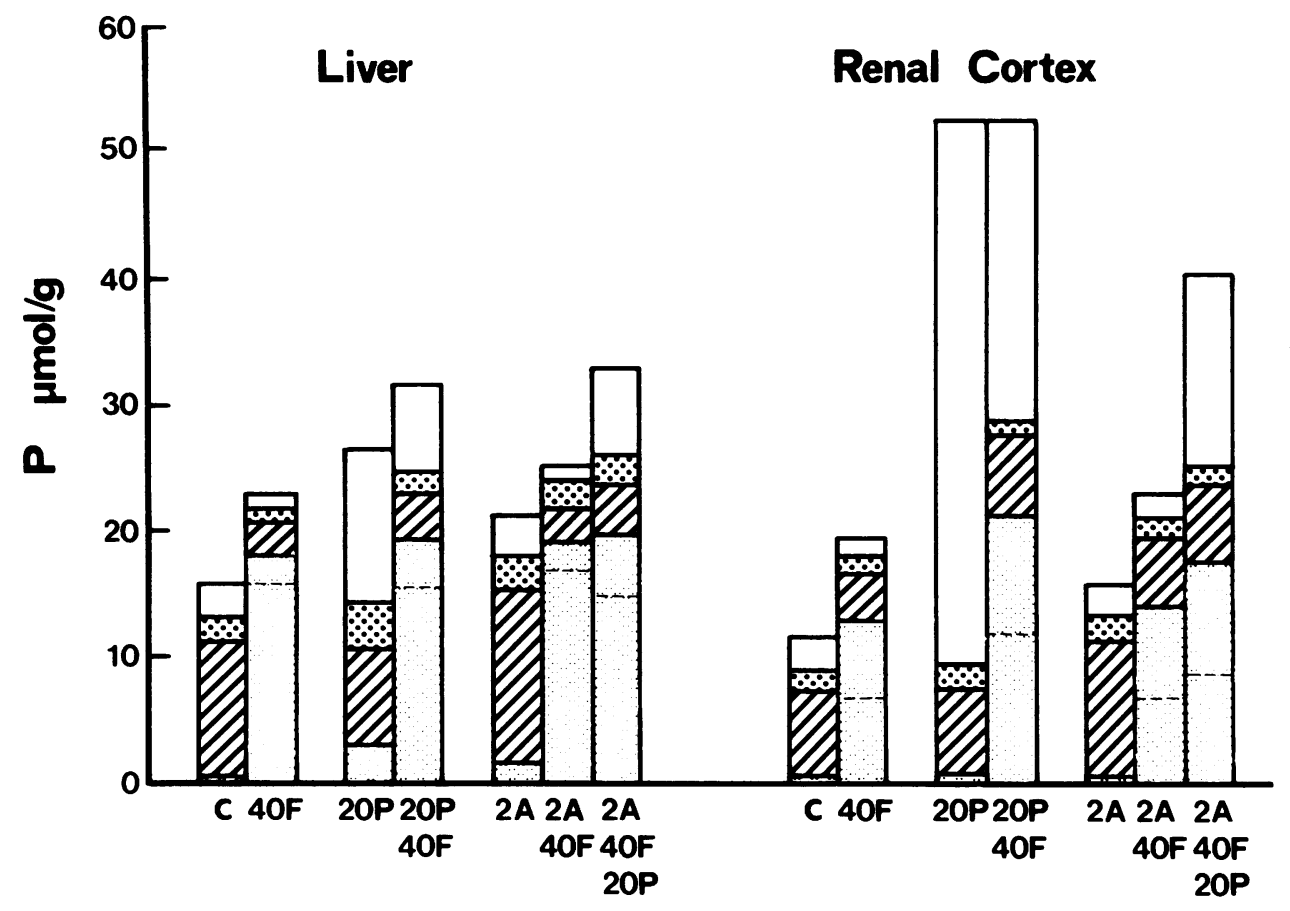

FIGURE 3 The effect of administering fructose (F) alone, and in combination with sodium phosphate (P), and adenosine (A) on the quantitative distribution of phosphorus among certain metabolites in liver and renal cortex. The doses of each substance administered in micromoles per gram body weight are indicated by the number next to its notation. The total amount of phosphorus ( $\mu \mathrm{mol} / \mathrm{g}$ wet weight) in the metabolites measured is indicated by the height of the columns. In descending sequence the component metabolites are $(a) P_{1}$ (open); (b) AMP + ADP; (c) ATP; (d) the sum of $\alpha$-glycerolphosphate + glucose-6-phosphate + fructose6-phosphate; and, when fructose was administered, (e) F-1-P. The amount of phosphorus in each component is calculated directly from the data of Tables I and II.

gain in molar concentration of organic phosphorus in the renal cortex with combined fructose-phosphate loading was $19-20 \mu \mathrm{mol} / \mathrm{g}$ compared to a gain of 9 with fructose loading alone (Table III, Fig. 3). Thus, in the renal cortex, the net gain in molar concentration of organic phosphorus that could be attributed to phosphate loading (in combination with fructose loading) was $10 \mu \mathrm{mol} / \mathrm{g}$, a gain more than three times the relatively small gain in the liver that could be attributed to phosphate loading (in combination with fructose loading), and a gain slightly greater than that induced by fructose alone in either the renal cortex or the liver.

\section{DISCUSSION}

The results of the current studies confirm that in the rat fructose loading induces an accumulation of F-1-P and a dose-dependent reduction of ATP in both the liver (17-20) and renal cortex (17), and in the liver, a dose-dependent reduction of $P_{1}$ and TAN (17-20). The current studies demonstrate further that fructose loading also induces a reduction of $P_{i}$ and dosedependent reduction of TAN in the renal cortex. The reductions of $P_{i}$ and TAN in the renal cortex, like the reduction of ATP and the accumulation of F-1-P in that tissue, are less severe than those in the liver. In the domain of reduced and control values of $P_{i}$ taken from both liver and renal cortex, ATP varied directly with $P_{i}$. Phosphate loading strikingly attenuates the reductions of ATP and TAN in the renal cortex, significantly attenuates them in the liver, and doubles renal cortical F-1-P. With respect to the renal cortical (but not hepatic) reductions of ATP and TAN, the attenuating effect of phosphate loading is substantially greater when its initiation precedes that of fructose loading by even $90 \mathrm{~s}$. Indeed, with this sequence and interval, fructose loading fails to induce a significant reduction in renal cortical TAN, and the reduction in renal cortical ATP is modest. When either the sequence is reversed, or the initiation of fructose and phosphate coincide, fructose loading induces a significant reduction in renal cortical TAN, and the reduction in renal cortical ATP is substantial. With phosphate loading alone, the renal cortical and hepatic concentrations of TAN and ATP are not increased. As judged from the phosphate balance data, with either 
phosphate/fructose or fructose/phosphate, the phosphate administered accounts for large and similar net gains of phosphate in the renal cortex and small net gains in the liver. These findings provide strong evidence that in the fructose-loaded rat: $(a)$ In both the renal cortex and the liver, depletion of $P_{i}$ is critical to the causation of the reductions of ATP and TAN. (b) In both tissues the severity of the depletion of $P_{i}$ determines the severity of the reduction in ATP and TAN. (c) In the renal cortex, as in the liver (16), the depletion of $P_{i}$, and the reduction in ATP and TAN, occur almost immediately. $(d)$ In the renal cortex, but not in the liver, prior administration of phosphate can largely prevent the depletion of $\mathrm{P}_{\mathrm{i}}$, at least at those sites in the cell where reduction of $P_{i}$ actuates whatever mechanisms cause the reductions of ATP and TAN. (e) In both tissues the reductions of ATP and TAN are to a large extent not reversed by replenishment of cellular $P_{i}$.

The attenuating effect of phosphate loading, and its striking, time-dependent magnitude in the renal cortex, provide strong support for the hypothesis of Mäenpää and his co-workers (16): In the liver (and renal cortex) of the fructose-loaded rat, depletion of $P_{i}$ causes reductions of TAN and ATP by causing activation of the cytoplasmic enzyme, AMP deaminase. (AMP, ADP, and ATP are maintained in equilibrium in the cytoplasm by the action of adenylate kinase.) The activity of AMP deaminase in the renal cortex is at least as great as that in the liver (49) and would appear to reflect the same isoenzyme (50). In the renal cortex, as in the liver, the deamination of AMP to inosine $5^{\prime}$-monophosphate can be brisk (51). In the isolated liver perfused with fructose, $10 \mathrm{mM}$, increasing the concentration of $P_{i}$ in the perfusion medium from 1 to $10 \mathrm{mM}$ prevented an otherwise sevenfold increase in concentration of inosine 5 '-monophosphate (19). The deamination reaction is essentially irreversible. Accordingly, if in both the liver and renal cortex of the fructose-loaded rat, depletion of $P_{i}$ is near immediate and AMP deaminase is activated immediately thereby, an enhanced degradation of adenine nucleotides mediated by this activation would predictably be prevented by phosphate loading only in the renal cortex, and only if initiated before fructose loading, and if only briefly, given the special access of extracellular $P_{i}$ into parenchymal cells of the renal cortex, and into these cells only.

Bode et al. (20) concluded that in the liver of the fructose-loaded rat, the reduction in cellular $P_{i}$ perturbed the metabolism of adenine nucleotides only by increasing their degradative rate via augmented deamination (and dephosphorylation of AMP). The investigators emphasized that the simultaneous administration of equimolar amounts of fructose and $P_{i}$ was attended by a significantly higher hepatic concentra- tion of AMP than that obtaining with administration of fructose alone; the hepatic concentration of ATP and TAN, however, were not significantly higher. They argued that fructose loading induced a reduction of hepatic ATP because of the rapid consumption of ATP in phosphorylating fructose to F-1-P. But in the present study the attenuation of the fructose-induced reduction in ATP observed with phosphate loading cannot be the consequence of a decrease in the consumption of ATP in phosphorylating fructose or its metabolites, or the consequence only of a decrease in the rate at which, or extent to which, adenine nucleotides are degraded.

With combined phosphate/fructose loading, not only was the fructose-induced reduction of renal cortical concentration of ATP almost prevented, but also the greater concentration of ATP occurred despite evidence of increased consumption of renal cortical ATP. Because the renal cortex and the liver both contain the enzyme cluster, fructokinase, aldolase " $B$ " and triokinase (52), both these tissues extract fructose briskly and convert it to glucose, predominantly, if not exclusively, by way of F-1-P and the triose products of its aldolase cleavage, D-glyceraldehyde and dihydroxyacetonephosphate $(16,17,19,27,53-56)$. For each mole of fructose so converted (or converted to $\alpha$ glycerolphosphate) $2 \mathrm{~mol}$ of ATP are consumed, one in converting fructose to $\mathrm{F}-1-\mathrm{P}$; one in converting $\mathrm{D}$ glyceraldehyde to D-glyceraldehyde phosphate (or in converting glycerol, the reduction product of Dglyceraldehyde, to $\alpha$-glycerol-phosphate). As judged from plasma and tissue concentrations of fructose and glucose and tissue concentrations of fructose6-phosphate and glucose-6-phosphate, the rate at which the renal cortex and the liver converts fructose to glucose is substantially lower at the higher fructose load. Prior phosphate loading, however, more than prevents this decrease in rate in the renal cortex and attenuates it in the liver. As judged from the phosphorus balance data, with combined fructose-phosphate loading, large amounts of administered phosphate not only enter the cells of the renal cortex but are used there to generate ATP. These findings provide evidence that in both the liver and renal cortex of the fructose-loaded rat, the greater depletion of $P_{i}$ at the higher load of fructose restricts regeneration of ATP to a rate substantially less than that obtaining at the lower load of fructose; and prior phosphate loading, by differentially mitigating these tissues' depletion of $\mathrm{P}_{\mathrm{i}}$, removes this rate restriction in the renal cortex and greatly attenuates it in the liver.

It could be argued that the mechanism through which phosphate loading ameliorates the fructoseinduced disturbance in adenine nucleotide metabolism depends on some effect of hyperphosphatemia per se, as well as, or instead of, that of mitigating cellular depletion of $P_{i}$ in the liver and renal cortex. With 
combined adenosine/fructose loading, however, the renal cortical concentration of ATP is as high as that obtaining with fructose/phosphate loading despite hypophosphatemia as severe as that induced by fructose alone. Furthermore, adenosine loading enhances the otherwise dampened renal cortical conversion of fructose to glucose. These results would appear not to be the consequence only of the supraphysiological renal cortical concentration of ATP that presumably obtained when fructose loading was initiated. With combined adenosine/fructose loading, the concentration of ATP attained in the liver can be presumed to have been not only transiently supraphysiological but initially greater than that attained in the renal cortex. Yet, hepatic conversion of fructose to glucose appears not to have been affected by adenosine loading. Clearly, the presumably greater decrease in hepatic concentration of ATP that occurs with combined adenosine/fructose loading, compared to that decrease which occurs with fructose loading alone, cannot be attributed to a greater consumption of ATP in converting fructose to glucose.

In the renal cortex, but not in the liver, the concentration of $P_{i}$ is significantly greater with combined adenosine/fructose loading than with fructose loading alone. Hence, with combined adenosine/fructose loading, as with fructose loading alone, the concentration of $P_{i}$ in the renal cortex is substantially greater than that in the liver. The activity of AMP deaminase varies not only inversely with the concentration of $P_{i}$ but directly with the concentration of total adenine nucleotides (26). It is perhaps not surprising then that the hepatic and renal cortical concentrations of TAN were 6.15 and $4.42 \mu \mathrm{mol} / \mathrm{g}$, respectively, with adenosine loading alone, and 1.85 and $2.72 \mu \mathrm{mol} / \mathrm{g}$, respectively, with combined adenosine/fructose loading. With combined adenosine/fructose loading, both the hepatic and renal cortical concentrations of TAN are greater than those obtaining with fructose loading alone, but the increment in the renal cortex is twice that in the liver. The renal cortical, but not hepatic, concentration of AMP is significantly greater with combined adenosine/fructose loading than with fructose loading alone. These findings provide evidence that initiating adenosine loading before fructose loading selectively attenuates the fructose-induced depletion of $P_{i}$ in the renal cortex, and as a consequence, selectively dampens the degradative rate of renal cortical adenine nucleotides in the renal cortex. In providing evidence that the selective attenuation of the reduction in renal cortical $P_{i}$ selectively attenuates the fructose-induced reduction in the rate at which the renal cortex converts fructose to glucose, the findings with combined adenosine/fructose loading provide further evidence that the rate at which the renal cortex can consume ATP in converting fructose to glucose depends critically upon, and varies directly with, cellular $P_{i}$ in this tissue.

In the liver and renal cortex of the fructose-loaded rat, depletion of cellular $P_{i}$ could restrict the rate at which ATP is regenerated by the mitochondria. In the isolated, perfused rat liver, Hassinen and Ylikhari demonstrated a Crabtree-like effect of fructose on oxygen uptake (57). In the isolated rat liver perfused with unrecirculating solution containing fructose, $10 \mathrm{mM}$, and $P_{i}$, either 1.2 or $5.0 \mathrm{mM}$, Sestoft found that the oxygen uptake was limited by $P_{i}$ at the lower concentration $(27,58)$. After $40 \mathrm{~min}$ of perfusion at the higher concentration of $P_{i}, 5.0 \mathrm{mM}$, the uptake of $\mathrm{O}_{2}$ was $16 \%$ greater than at the lower concentrations and the tissue concentration of ATP was significantly greater, $1.45 \mathrm{vs} .1 .15 \mu \mathrm{mol} / \mathrm{g}$ wet wt. Since the $K_{m}$ for fructokinase with respect to ATP is between 0.2 (59) and $1.5 \mathrm{mM}(60,61)$, the higher concentration of ATP could explain the observation that the elimination of fructose was greater at the higher perfusion concentration of $P_{i}(27,58)$. The enhanced elimination of fructose attending the higher concentration of $\mathrm{P}_{\mathrm{i}}$ occurred within $10 \mathrm{~min}$ of initiating the perfusion and appeared to be a steady-state phenomenon over the subsequent $30 \mathrm{~min}$. Sestoft proposed that in the rat liver perfused with fructose, cellular $P_{i}$ controls mitochondrial respiration and thereby the concentration of ATP and the rate of fructose phosphorylation $(27,58)$. In this connection, in the current study, the apparent rate at which the renal cortex metabolized the higher load of fructose varied directly with the renal cortical concentration of ATP, as increased by the different schedules and combination of phosphate (and adenosine) loading.

Sestoft seemed to discount the possibility that, in the isolated liver perfused with fructose, increasing the perfusion concentration of phosphate substantially decreased the degradative rate of AMP (and hence TAN) $(58,62)$. He emphasized that at the higher perfusion $P_{i}$, the higher tissue concentration of ATP was attended by a "counter-poise" in tissue concentration of AMP (62). Furthermore, the tissue concentration of TAN at the higher perfusion $P_{i}$ was not significantly greater than the reduced values obtaining at the lower perfusion $P_{i}$. Undoubtedly, in the isolated liver perfused with fructose and phosphate, Sestoft's observations support his placement of the site of connection between fructose and phosphate metabolism in the mitochondria. Indeed, his observations strongly suggest that in the fructose-perfused liver the rate of mitochondrial synthesis of ATP can be made to vary directly with cellular $P_{i}$ and independently of an even greatly reduced pool size of adenine nucleotides. But in the present study of intact rats, the renal and hepatic concentrations of total adenine nucleotides, as well as of ATP, were significantly greater when fructose was 
administered in combination with sodium phosphate than when fructose was administered alone. Furthermore, the renal cortical concentration of ATP attained with phosphate loading would not have been possible without the greater concentration of total adenine nucleotides. Specifically, with combined phosphate/ fructose loading, the renal cortical concentration of ATP was $2.03 \pm 0.33 \mu \mathrm{mol} / \mathrm{g}$; with fructose loading alone the renal cortical concentration of total adenine nucleotides was only $2.16 \pm 0.16$. It seems likely then that in both the renal cortex and liver of the fructose-loaded rat, severe cellular depletion of $P_{i}$ both mediates the reduction in pool size of adenine nucleotides and restricts the rate of mitochondrial respiration, and, by determining the extent of both phenomena, determines both the concentration and rate of regeneration of ATP.

\section{ACKNOWLEDGMENTS}

We thank Susan Curley for her expert typing.

This investigation was supported by grants from the United States Public Health Service, National Institutes of Health: Institute of Arthritis, Metabolism, and Digestive Diseases (AM 16764) and by Clinical Research Centers Branch, Division of Research Resources (RR-00079).

\section{REFERENCES}

1. Froesch, E. R. 1966. Essential fructosuria and hereditary fructose intolerance. In The Metabolic Basis of Inherited Disease. J. B. Stanbury, J. B. Wyngaarden, and D. S. Fredrickson, editors. 2nd edition. McGraw-Hill Book Co., New York. 131-148.

2. Hers, H. G., and G. Joassin. 1961. Anomalie de l'aldolase hepatique dans l'intolerance au fructose. Enzymol. Biol. Clin. 1: 4-14.

3. Morris, R. C., Jr., I Ueki, D. Loh, R. Z. Eanes, and P. McLin. 1967. Absence of renal fructose-1-phosphate aldolase activity in hereditary fructose intolerance. $\mathrm{Na}$ ture (Lond.). 214: 920-921.

4. Nisell, J., and L. Linden. 1968. Fructose-1-phosphate aldolase and fructose-1,6-diphosphate aldolase activity in the mucosa of the intestine in hereditary fructose intolerance. Scand. J. Gastroenterol. 3: 80-82.

5. Perheentupa, J., and K. Raivio. 1967. Fructose-induced hyperuricaemia. Lancet. II: 528.

6. Morris, R. C., Jr. 1968. An experimental renal acidification defect in patients with hereditary fructose intolerance. II. Its distinction from classic renal tubular acidosis; its resemblance to the renal acidification defect associated with the Fanconi syndrome of children with cystinosis. J. Clin. Invest. 47: 1648-1663.

7. Morris, R. C., Jr. 1968. An experimental renal acidification defect in patients with hereditary fructose intolerance. I. Its resemblance to renal tubular acidosis. J. Clin. Invest. 47: 1389-1398.

8. Van den Berghe, G., L. Hue, and H. G. Hers. 1973. Effect of the administration of fructose on the glycogenolytic action of glucagon. An investigation of the pathogeny of hereditary fructose intolerance. Biochem. J. 134: 637-645.

9. Kaufman, U., and E. R. Froesch. 1973. Inhibition of phosphorylase by fructose-1-phosphate, $\alpha$-glycerophos- phate and fructose-1,6-diphosphate: Explanation for fructose-induced hypoglycaemia in hereditary fructose intolerance and fructose-1,6-diphosphatase deficiency. Eur. J. Clin. Invest. 3: 407-413.

10. Rambaud, P., A. Joannard, M. Bost, A. Marchal, M. Rachail, and J. Roget. 1973. Trouble de la glycogenolyse dans l'intolerance hereditaire au fructose. Etude de deux observations chez l'enfant. Arch. Fr. Pediatr. 30: 10511062.

11. Thurston, J. H., E. M. Jones, and R. E. Hauhart. 1974. Decrease and inhibition of liver glycogen phosphorylase after fructose. Diabetes. 23: 597-604.

12. Sidbury, J. B., Jr. 1959. Zur Biochemie der hereditaren Fructose-intoleranz. Helv. Paediatr. Acta. 14: 317-318.

13. Zalitis, J., and I. T. Oliver. 1967. Inhibition of glucose phosphate isomerase by metabolic intermediates of fructose. Biochem. J. 102: 753-759.

14. Morris, R. C., Jr., A. Sebastian, and E. McSherry. 1972. Renal acidosis. Kidney Int. 1: 322-340.

15. Morris, R. C., Jr., R. R. McInnes, C. J. Epstein, A. Sebastian, and C. R. Scriver. 1976. Genetic and metabolic injury of the kidney. In The Kidney. B. M. Brenner and F. C. Rector, Jr., editors. W. B. Saunders Co., Philadelphia. 1193-1256.

16. Mäenpää, P. H., K. O. Raivio, and M. P. Kekomäki. 1968. Liver adenine nucleotides: fructose-induced depletion and its effect on protein synthesis. Science (Wash. D. C.). 161: 1253-1254.

17. Burch, H. B., O. H. Lowry, L. Meinhardt, P. Max, Jr., and K-J. Chyu. 1970. Effect of fructose, dihydroxyacetone, glycerol, and glucose on metabolites and related compounds in liver and kidney. J. Biol. Chem. 245: 2092-2102.

18. Woods, H. F., L. V. Eggleston, and H. A. Krebs. 1970. The cause of hepatic accumulation of fructose-1-phosphate on fructose loading. Biochem. J. 119: 501-510.

19. Woods, H. F. 1972. Hepatic accumulation of metabolites after fructose loading. Acta Med. Scand. Suppl. 542: 87-103.

20. Bode, J. C., O. Zelder, H. F. Rumpelt, and U. Wittkamp. 1973. Depletion of liver adenosine phosphates and metabolic effects of intravenous infusion of fructose or sorbitol in man and in the rat. Eur. J. Clin. Invest. 3: 436-441.

21. Heuckenkamp, P-U., and N. Zollner. 1971. Fructoseinduced hyperuricemia. Lancet. I: 808-809.

22. Fox, I. H., and W. M. Kelley. 1972. Studies on the mechanism of fructose-induced hyperuricemia in man. Metab. Clin. Exp. 21: 713-721.

23. Raivio, K. O., M. A. Becker, L. J. Meyer, M. L. Greene, G. Nuki, and J. E. Seegmiller. 1975. Stimulation of human purine synthesis de novo by fructose infusion. Metab. Clin. Exp. 24: 861-869.

24. Hultman, E., L. H. Nilsson, and K. Sahlin. 1975. Adenine nucleotide content of human liver. Normal values and fructose-induced depletion. Scand. J. Clin. Lab. Invest. 35: 245-251.

25. Nikiforuk, G., and S. P. Colowick. 1956. The purification and properties of 5-adenylic acid deaminase from muscle. J. Biol. Chem. 219: 119-129.

26. Chapman, A. G., and D. E. Atkinson. 1973. Stabilization of adenylate energy charge by the adenylate deaminase reaction. J. Biol. Chem. 248: 8309-8312.

27. Sestoft, L. 1974. Regulation of fructose metabolism in the perfused rat liver: Interrelation with inorganic phosphate, glucose, ketone body and ethanol metabolism. Biochim. Biophys. Acta. 343: 1-16.

28. Desbuquois, B., R. Lardinois, C. Gentil, and M. Odievre. 1969. Effects d'une surcharge en phosphate de sodium 
sur l'hypoglucosémie dans onze observations d'intolérance héréditaire au fructose. Arch. Fr. Pediatr. 26: $21-$ 35.

29. Nivelon, J-L., M. Mathieu, C. Kissin, C. Collombel, J. Cotte, and M. Béthenod. 1967. Intolérance au fructose. Observation et mécanisme physiopathologique de l'hypoglucosémie. Ann. Pediatr. 43: 817-824.

30. Perheentupa, J., K. O. Raivio, and E. A. Nikkila. 1972. Hereditary fructose intolerance. Acta. Med. Scand. Suppl. 542: 65-75.

31. Till, U., D. Brox, and H. Frunder. 1969. Orthophosphate turnover in the extracellular space and intracellular space of mouse liver. Eur. J. Biochem. 11: 541-548.

32. Schmidt, U., and U. C. Dubach. 1971. Quantitative histochemia an nephron. Prog. Histochem. Cytochem. 2: 185-298.

33. Goldberg, M., Z. S. Agus, and S. Goldfarb. 1976. Renal handling of phosphate, calcium and magnesium In The Kidney. B. M. Brenner, and F. C. Rector, Jr., editors. W. B. Saunders Co., Philadelphia. 344-390.

34. Hoffman, N., M. Thees, and R. Kinne, 1976. Phosphate transport by isolated renal brush border vesicles. Pfleugers Arch. Eur. J. Physiol. 362: 147-156.

35. Strehler, B. L., and J. R. Totter. 1954. Determinations of ATP and related compounds: firefly luminescence and other methods. Methods Biochem. Anal. 1: 341.

36. Adam, H. 1963. Adenosine-5'-monophosphate and adenosine-5'-diphosphate. In Methods of Enzymatic Analysis. H. U. Bergmeyer, editor. Academic Press, Inc., New York. 573-577.

37. Fiske, C. H., and U. SubbaRow. 1925. The colorimetric determination of phosphorus. J. Biol. Chem. 66: 375400.

38. Lowry, O. H., and J. A. Lopez. 1946. The determination of inorganic phosphate in the presence of labile phosphate esters. J. Biol. Chem. 162: 421-428.

39. Lowry, O. H., J. V. Passoneau, F. X. Hasselberger, and D. W. Schulz. 1964. Effect of ischemia on known substrates and cofactors of the glycolytic pathway in brain. J. Biol. Chem. 239: 18-30.

40. Klotzsch, H., and H. U. Bergmeyer. 1963. D-Fructose. In Methods of Enzymatic Analysis. H. E. Bergmeyer, editor. Academic Press, Inc., New York. 156-159.

41. Hohorst, H. J. 1963. D-glucose-6-phosphate and D-fructose-6-phosphate. Determination with glucose-6-phosphate dehydrogenase and phosphoglucose isomerase. In Methods of Enzymatic Analysis. H. U. Bergmeyer, editor. Academic Press, Inc., New York. 134-138.

42. Raivio, K. O., M. P. Kekomäki, and P. H. Mäenpää. 1969. Depletion of liver adenine nucleotides induced by $D$-fructose: dose-dependence and specificity of the fructose effect. Biochem. Pharmacol. 18: 2615-2624.

43. Faupel, R. P., H. J. Seitz, W. Tarnowski, V. Thiemann, and $\mathrm{Ch}$. Weiss. 1972. The problem of tissue sampling from experimental animals with respect to freezing technique, anoxia, stress and narcosis: A new method for sampling rat liver tissue and the physiological values of glycolytic intermediates and related compounds. Arch. Biochem. Biophys. 148: 509-522.

44. Hems, D. A., and J. T. Brosnan. 1970. Effects of ischaemia on content of metabolites in rat liver and kidney in vivo. Biochem. J. 120: 105-111.

45. Chagoya de Sánchez, V., A. Brunner, and E. Piña. 1972.
In vivo modification of the energy charge in the liver cell. Biochem. Biophys. Res. Commun. 46: 1441-1445.

46. Chagoya de Sánchez, V., A. Brunner, M. E. Sánchez, C. Lopez, and E. Piña. 1974. Utilization of adenosine as a tool in studies on the regulation of liver glycogen biosynthesis. Arch. Biochem. Biophys. 160: 145-150.

47. Lund, P., N. W. Cornell, and H. A. Krebs. 1975. Effect of adenosine on the adenine nucleotide content and metabolism of hepatocytes. Biochem. J. 152: 593599.

48. Wilkening, J., J. Nowack, and K. Decker. 1975. The dependence of glucose formation from lactate on the adenosine triphosphate content in the isolated perfused rat liver. Biochim. Biophys. Acta. 392: 299-309.

49. Lowenstein, J. M. 1972. Ammonia production in muscle and other tissues: the purine nucleotide cycle. Physiol. Rev. 52: 382-414.

50. Ogasawara, N., H. Goto, and T. Wantanabe. 1975. Isoenzymes of rat AMP deaminase. Biochim. Biophys. Acta. 403: 530-537.

51. Bogusky, R. T., L. M. Lowenstein, and J. M. Lowenstein. 1976. The purine nucleotide cycle. A pathway for ammonia production in the rat kidney. J. Clin. Invest. 58: $326-335$.

52. Kranhold, J. F., D. Loh, and R. C. Morris, Jr. 1969. Renal fructose-metabolizing enzymes: Significance in hereditary fructose intolerance. Science (Wash. D.C.). 165: 402-403.

53. Hers, H. G. 1955. The conversion of fructose-1-C ${ }^{14}$ and sorbitol-1-C $\mathrm{C}^{14}$ to liver and muscle gl cogen in the rat. J. Biol. Chem. 214: 373-381.

54. Salomon, L. L., F. L. Lanza, and D. E. Smith. 1961. Renal conversion of fructose to glucose. Am. J. Physiol. 200: 871-876.

55. Lee, J. B., V. K. Vance, and G. F. Cahill, Jr. 1962. Metabolism of $\mathrm{C}^{14}$-labeled substrates by rabbit kidney cortex and medulla. Am. J. Physiol. 203: 27-36.

56. Landau, B. R., J. S. Marshall, J. W. Craig, K. Y. Hostetler, and S. M. Genuth. 1971. Quantitation of the pathways of fructose metabolism in normal and fructoseintolerant subjects. J. Lab. Clin. Med. 78: 608-618.

57. Hassinen, I., and R. H. Ylikhari. 1970. Absorption spectrophotometry of perfused rat liver applied to fructoseinduced inhibition of respiration. Biochem. Biophys. Res. Commun. 38: 1091-1097.

58. Sestoft, L. 1974. Regulatory processes in rat liver induced by sudden changes in fructose concentration. In Regulation of Hepatic Metabolism. F. Lundquist, and N. Tygstrup, editors. Munksgaard, Copenhagen. 285-301.

59. Parks, R. E., Jr., E. Ben-Gershom, and H. A. Lardy. 1957. Liver fructokinase. J. Biol. Chem. 227: 231-242.

60. Adelman, R. C., R. J. Ballard, and S. Weinhouse. 1967. Purification and properties of rat liver fructokinase. $J$. Biol. Chem. 242: 3360-3365.

61. Sanchez, J. J., N. A. Gonzales, and H. G. Pontis. 1971. Fructokinase from rat liver. II. The role of $\mathrm{K}+$ on the enzyme activity. Biochim. Biophys. Acta. 227: 79-85.

62. Bode, J. C., C. Bode, H. J. Rumpelt, and O. Zelder. 1974. Loss of hepatic adenosine phosphate and metabolic consequences following fructose or sorbitol administration in man and in the rat. In regulation of Hepatic Metabolism. F. Lundquist, and N. Tygstrup, editors. Munksgaard, Copenhagen. 267-284. 